\title{
Rape myth in true and false rape allegations.
}

\section{Russell Norton and Tim Grant}

Russell Norton

Psychological Assistant, HMP Channings Wood, Denbury,

Newton Abbot,

Devon,

TQ12 6DW
Dr Tim Grant

Forensic Section

School of Psychology

University of Leicester

106 New Walk

Leicester

LE1 7EA

TG21@le.ac.uk

(Author for all correspondence.) 


\title{
Rape myth in true and false rape allegations.
}

\begin{abstract}
Police records of 38 rape allegations, evenly split into maintained-as-true and withdrawn-as-false categories were compared to 19 generated false statements from recruited participants. The Illinois Rape Myth Acceptance Scale (IRMAS) was used to assess the attitudes of the participants and a content analysis derived from IRMAS was used to compare the three categories of allegation. Rape myths were present in all three allegation types. The two categories of false allegation both contained more rape myths than the true allegations but no differences were found between the generated and withdrawn false allegations. High scorers in IRMAS also produced more violent false accounts. In addition to these findings this study provides support for the further examination of rape myths in both false and true statements and use of generated allegations as proxies for real false statements.
\end{abstract}

\section{Key words}

Rape, stereotype, myth, true, false, allegations, IRMAS

\section{Acknowledgments}

The authors would like to thank the Serious Crime Analysis Section at Centrex for their support and access to the data which forms the basis of this study. 


\section{INTRODUCTION}

It has been estimated that $2 \%$ of all rape allegations made are false (Lonsway \& Fitzgerald, 1994; Allison \& Wrightman, 1993), given that the reported number of rapes in the United Kingdom exceeded 14,000 between 2005-2006 (Walker, Kershaw \& Nicholas, 2006), this figure may reflect approximately 280 cases per annum in the UK. There is considerable psychological literature which considers the detection of deception (e.g. Vrij, 2000; 2005) and there have been various recent attempts which focus on markers for distinguishing between true and false rape allegations (Rassin \& van der Sleen, 2005, Burgess and Hazelwood, 2001; Woodhams \& Grant, 2004).

Previous work by Rainbow (1996) concentrated on the alleged behaviours of the rapist and which behaviours are likely to co-occur in reality. Rainbow compared allegations maintained-as-true within police files with some supporting evidence for their veracity but he used accounts constructed by participants as his false condition. Written statements were used because it was felt mock police interviews could have evoked distress from the participants (Ofshe \& Walters, 1998; Ryan, 1988). This may reduce ecological validity considering actual allegers of rape may be experiencing distress through making an allegation. Rainbow's findings identified that false accounts contained a greater frequency of stereotypical rape behaviours such as touching the victim's breasts, the victim closing her eyes and fainting and that cooccurrence of behaviours created different patterns in the true and false conditions. This use of elicited rather than collected false allegations raises interesting questions of ecological validity but to date there has been no comparison of real statements 
which are believed to be false and constructed allegations provided by general population. One purpose of the current study is to in part address this issue.

Woodhams and Grant (2004) conducted a study employing a sample of allegations which were maintained-as-true and had some collaborative police evidence and compared these with allegations which were withdrawn-as-false, again with some collaborative evidence as to falsity. They examined the content of the conversation between the attacker and victim as revealed in the allegations using a coding scheme devised for this purpose (Woodhams \& Grant, 2006) finding less talk in the false condition with fewer directives, interrogatives and commissives and that the utterances were more polite and more specific but less threatening than in the true condition.

Both Rainbow (1996) and Woodhams and Grant (2006) generated hypotheses around the idea that the false allegations would reflect rape myths found in the general population. Rape myths constitute stereotypical beliefs about rape (Peterson \& Muelhenhard, 2004; Payne, Lonsway \& Fitzgerald, 1999; Cahill, 2000) which may arise through media amplification of sensational cases of rape (Kahn \& Mathie, 2000). This shifts the extreme cases on a spectrum of offending, to be represented as a norm, hence rape myths may not be untrue but rather an over-representation of an extremity of offending. Given this, the concept of rape myth might be better formulated as a rape stereotype. The body of literature surrounding attitudes towards rape uses the terms myths and stereotypes interchangeably (George \& Martinez, 2002). Myths and stereotypes arguably both contain aspects of truth and falsity. The term "myth" is suggestive of a benign construct that is useful to retain considering it 
historically colours aspects of the cultural climate and can be used as a tool for exploring it. Kelly, Lovett and Regan (2005) suggest that the concept of a stereotype is a more powerful reframing of the issue. This may be because the label "stereotype" suggests individually relevant attitudes that may be acted upon and have generally been considered more damaging contemporarily rather than useful as an explanatory tool. Indeed Kelly, Lovett and Regan (2005) found that at various stages of the investigative process stereotypical 'real' rapes are advantaged over more common but less stereotypical rape and that this leads to attrition of rape prosecution in the courts. As such stereotypes have been actively targeted to reduce their damaging effects. Their work has contributed in part to recent UK Home Office campaigns attacking rape stereotypes; addressing particularly the issue of consent (Home Office, 2006). Therefore this study would advocate reframing benign rape myths as malignant rape stereotypes.

This paper will now consider some of the measures for rape myths, within this we now refer to myths as stereotypes; however retain the original titles of the scales. It is important to be aware that making reference to stereotypes may be inaccurate considering the scales are based on rape myths. However it is arguable that the items that constitute these scales are actual stereotypical statements about rape. The most influential measure of rape stereotypes is Burt's (1980) Rape Myth Acceptance Scale, however it has been criticised for having out-dated terminology and lacking sensitivity to demographic variables other than gender, which might interact with rape stereotype acceptance (Payne, Lonsway \& Fitzgerald, 1999). It was also identified that some items reflected rape stereotypes that were common sense and cyclical. A further limitation is that there are only three subscales; sexual conservation, 
adversarial sexual beliefs and interpersonal violence. A more recent tool is the Illinois Rape Myth Acceptance Scale (IRMAS), which uses seven subcategories to provide a richer description of rape stereotypes (see appendix 1). Payne, Lonsway and Fitzgerald (1999) demonstrated the IRMAS to be internally consistent and reliable for both surface and subscales, with adequate construct validity through a series of studies. At present no study has applied any rape stereotype acceptance scale to individuals constructing false rape allegations, this would be important for assessing whether construction is based on internal attitudes.

It could be predicted from this body of literature that false rape allegations would contain a greater frequency of rape stereotypes than true allegations because they are dependent on individual beliefs and social concepts rather than an actual experience (Morton \& Duck, 2003). However it would also need to be investigated whether exposure to knowledge of rape stereotypes would confound this prediction. For example, a review of the literature identifies that younger individuals systematically had a greater acceptance of rape stereotypes and tended to blame the victim more (Kershner, 1996). This finding suggests that younger individuals lack the actual personal experience to inform their beliefs and therefore are more reliant on stereotypical concepts of sex and rape present within the media. It would therefore be very important when obtaining a sample to identify their degree of sexual experience and whether the sum of these experiences are generally positive/negative. Any experimental sample, therefore, should attempt to match the demographic features of the false alleger group to avoid a confound. Such a comparison of true and false allegations consistent with rape stereotypes would fall largely within Rassin and van der Sleen’s (2005) category of (non-verbal) contextual criteria. 
This study investigates three groups of allegations; maintained-as-true statements collected from police data, withdrawn-as-false statements collected from police data and false allegations generated experimentally from the general population. The main research question addressed is whether maintained-as-true, withdrawn-as-false and generated-false rape allegations differ in the quantity and quality of rape stereotype.

\section{METHOD}

\section{Participants}

The data set used in Woodhams and Grant (2004) was reanalysed in the current study, this was to address concerns as to falsity of withdrawn-as-false statements. This data consisted in 38 allegations of rape, drawn from police interviews, made by females against males from UK police files held by the Serious Crime Analysis Section (SCAS) of the National Crime and Operations Faculty (NCOF) situated at Bramshill in Hampshire, UK. Statements withdrawn-as-false were identified either through a credible and corroborated victim retraction or a prosecution for wasting police time. Maintained-as-true statements were matched on demographic and offence specific criteria.

For the generated-false statements, an opportunity sample of nineteen female participants was recruited through newspaper advertisements. Such a sample was felt to better represent motivated allegers of rape through having to approach the study rather than being actively recruited by it; this sample may also be more ecologically valid since it was elicited from the general public and not solely student samples. Maintained-as-true and withdrawn-as-false statements were demographically matched 
to each other. The recruited sample was matched to the withdrawn-as-false group by the demographic features they were required to include in their statement; such as whether the attacker was a stranger, how old he was, whether he acted on his own and whether penile penetration was involved. However, the mean age of the allegers from the police database was $17 \mathrm{yrs}(\mathrm{SD}=1.58)$; participants recruited for the knowinglyfalse condition had a mean age of 23 yrs $(S D=0.96)$. The advertisement requested participants aged 18-25, as in ethical and ecologically valid terms reporters of rape under 18 years old may require an adult presence (PACE, 2006). Participants rated themselves as either sexually experienced or inexperienced and rated these experiences on a scale as positive or negative; to identify whether personal experiences acted as a confound for acceptance of rape stereotypes and inclusion of these within false statements. No other demographic features were elicited from this group A non-response rate of seven participants was recorded, these were individuals who responded to the advert but did not complete the data collection pack.

\section{Materials}

Participants for the generated-false condition received a data-collection pack containing information about the study, consent forms and a vignette describing a situation in which Miss X decided to make a false allegation. Participants were told to include details in their statement that were matched to the withdrawn-as-false statements, for example that the offender was a stranger. They were then instructed to assume the role of Miss $\mathrm{X}$ and construct a false allegation:

"Start from the beginning, from the point you met to when you parted. Please give a full description including anything that was said.”

This was followed by a short battery of statements for participants to make judgements about the allegation, these were: 
“Please indicate how successful you feel Miss X's statement will be in increasing the chances of securing a conviction” on a seven-point Likert scale ranging from very unsuccessful to very successful.

"Please indicate how likely it would be that Miss $\mathrm{X}$ would want to change her statement if she could" on a seven-point Likert scale ranging from very unlikely to very likely.

On seven-point Likert scales participants indicated their personal level of sexual experience (ranging from very inexperienced to very experienced) and how positive/negative the sum of their experiences were (ranging from very negative to very positive).

The participants were then instructed to complete the IRMAS measure. This consists of a 21 items rated on a seven point agreement scale. The scale includes items such as "If the rapist doesn't have a weapon, you really can't call it rape.", "Rape is unlikely to happen in the woman's own familiar neighborhood." and "Women tend to exaggerate how much rape affects them."

A written debrief was presented to participants once the study was complete.

\section{Procedure}

For the generated-false group an advertisement was placed for female participants aged 18-25 years old in a regional paper for the south west. The general nature of the 
study was described and a $£ 50$ prize draw offered as recompense for time invested on the participants' part. Participants responded by post or email, detailing only their addresses or email, not their names so all correspondence was anonymous. Participants were assigned a participant number and their details were held on a secure database.

The data collection packs were e/mailed, postal packs contained pre-paid return envelopes. Once all data was collected debriefs were sent out and one participant was randomly selected to win the prize draw.

\section{Ethical issues}

Participants were informed of the nature of the study, what would be required of them and what possible negative effects there may have been. National rape help-lines and addresses were also provided for participants. All participants gave their consent and were informed of their right to withdraw at any point. After data collection participants were provided with a full debrief about the study and the National helplines/addresses were stated again, all participant contact details were erased. The study was also approved by the University of Leicester's Forensic Psychology Research and Ethics Committee.

\section{RESULTS}

\section{Content analysis}

Pattern codes were elicited for the content analysis of participant statements using the subcategories from the IRMAS. Items on the scale relating to the particular sub- 
category were used to identify rape stereotype themes in the texts which were highlighted in unitary constructs and vote-counted. Using the IRMAS to identify rape stereotypes added reliability to the study through using a scale widely accepted and verified in the literature as well as making comparisons between the participants IRMAS scores and their statements more salient.

In the analysis three sub-categories of the IRMAS were discarded on the basis that the concepts they embodied were not suitable for and in fact not found in the first-person accounts, these included: She wanted it, She lied about it and Rape is a trivial event. The final set of pattern codes were; She asked for it (SA), which encapsulated concepts relating to victim culpability. An example of such a coding might be "I felt guilty because I'd sort of led him on all night long, but I didn't deserve that did I?” [Generated-false statement (GF) 7]. It wasn't really rape (NR), involved the necessity for victim resistance, where a participant might indicate they had at least attempted to make their non-consent sufficiently clear; for example "I told him to get off me and said he'd got the wrong idea.” [GF7]. He didn't mean it (MT), related to concepts excusing the offender on the basis of his sex drive; for example "Once he had satisfied himself he withdrew from me.” [GF6] and Rape is a deviant event (DE), which related to pathological aspects of the environment, context or offender as an explanation for what happened. Such an example might be; "He pulled me into a secluded area of the park where few people go as there are lots of trees and it gets very dark” [GF6].

A further pattern code was created to encompass rape stereotypes which it was felt the IRMAS sub-categories did not account for and, this specifically involved the idea that 
rape required physical violence; e.g. "I was very scared and tried to slap him but he was very forceful and slapped me hard” [GF5]. Following more closely Burt’s RMAS subscale Interpersonal violence; this was labelled; Rapists are violent (RV). The sixth pattern code used was Neutral; this embodied all themes that were not related to rape stereotypes and was used with the other pattern codes to provide a benchmark for the total number of unitary concepts in the statements, from which rape stereotypes could be calculated as a percentage (RSP). This was more useful for identifying the total percentage of rape stereotypes present in the allegations than text length considering some concepts may involve more word-use than others, plus it allowed the percentages to be more comparable (see table 1 for total number of concepts present in statements).

The maintained-as-true and withdrawn-as-false statements were coded blind to reduce experimenter bias. Generated-false statements were not coded entirely naively considering the experimenter may have implicitly recognised these statements through removing them from the data-packs for anonymous coding. Recognising this as a serious methodological flaw reliability across all three conditions was addressed and verified by a second independent coder who was naïve as to the source of the statements and fully briefed as to the rationale for why each unitary concept had been coded as such. Recommendations through discussion with the independent coder were accepted to ensure homogeneity of coding.

The amounts of rape stereotypes along with demographical information and IRMAS scores are given in Table 1. 


\section{Between group differences in rape stereotypes.}

Although the individual content analysis codes showed no significant pattern of differences between the three groups, the total proportion of rape stereotypes (RSP) did show a pattern of difference (see Figure 1). RSP showed no difference from normal (K-S Z $=.832 ; n=57 ; \mathrm{p}=0.49)$ and no heterogeneity of variance was found (Levene $\left.\mathrm{F}_{(2,54)}=2.736 ; \mathrm{p}=0.074\right)$. A one-way ANOVA demonstrated differences between groups $\left(\mathrm{F}_{(2,57)}=29.21 ; \mathrm{p}<0.001\right.$; partial $\left.\eta^{2}=0.52\right)$. Scheffe post hoc testing revealed that maintained-as-true statements contained significantly fewer rape stereotypes than the two false conditions $(\mathrm{p}<0.001)$ and that there was no significant difference between the two false conditions on the measure of rape stereotypes.

-Figure 1 near here-

Within and between conditions some similarities and differences were found in the relationship between the individual codes. Within all conditions the 'Rapists are violent' code, inversely correlated with concepts relating to the victims culpability (Generated-false: $\mathrm{r}=-0.672, \mathrm{n}=19, \mathrm{p}<0.01$; Withdrawn-as-false: $\mathrm{r}=-0.562, \mathrm{n}=19$, $\mathrm{p}<0.05$; Maintained-as-true: $\mathrm{r}=-0.575, \mathrm{n}=19, \mathrm{p}>0.01$ ). In other words as reported descriptions of offender violence increased concepts relating to self-blame on the part of the victim decreased (and visa versa). Within both false conditions, accounts that included some consideration for the necessity of victim resistance inversely correlated with the idea that the woman had asked for it (Generated-false: $r=0.57, n=19$, $\mathrm{p}<0.05$; Withdrawn-as-false: $\mathrm{r}=0.485, \mathrm{n}=19, \mathrm{p}<0.05$ ). Therefore some a proportion of victim culpability was sought within false accounts but not maintained-as-true. 
In addition, within the withdrawn-as-false condition there was an inverse correlation between the idea that rape is a deviant event and concepts relating to victim culpability $(\mathrm{r}=0.563, \mathrm{n}=19, \mathrm{p}<0.05)$. Within the maintained-as-true condition 'Rapists are violent' inversely correlated with concepts indicating that the man did not really mean it $(\mathrm{r}=0.516, \mathrm{n}=19, \mathrm{p}<0.05,2$-tailed $)$; thus offender violence and concepts excusing the offender tended not co-occur in true accounts, but did in false accounts.

\section{Relationship between IRMAS and rape stereotypes in generated} accounts.

The question of whether the belief in rape stereotypes is related to more rape stereotypes appearing in false accounts was examined. This was done through a comparison of the RSP scores in generated accounts with participants IRMAS scores for each subscale and overall.

There were no significant correlations between the overall IRMAS score and the overall RSP score $(\mathrm{r}=0.413, \mathrm{n}=19, \mathrm{p}>0.05)$ or between IRMAS sub-scores and their specifically related content analysis codes. There was, however, a significant relationship between the IRMAS overall score and the occurrence of the 'Rapists are violent' code (Pearson $\mathrm{r}=0.57, \mathrm{n}=19, \mathrm{p}=0.01$ ) indicating that the individuals who generated more violent accounts were measured as believing more rape stereotypes overall. Furthermore there was an inverse relationship between the overall IRMAS score and the occurrence of "She asked for it" codes in these generated accounts (Pearson $r=-0.61, n=19, p=0.006)$. 


\section{Other issues}

No relationship was found between participant expectations of success or withdrawal of accounts and the amount of rape stereotypes found in generated false accounts. Examination of participants’ IRMAS and generated-false RSP scores showed no significant correlations with their own level of sexual experience or their rating of how positive/negative their experiences were, suggesting that the sample was either drawn from the same population or that variation in their sexual experiences had no impact on their belief in rape stereotypes, or their inclusion within elicited false accounts.

\section{DISCUSSION}

Overall the results identified that both generated false and withdrawn-as-false rape allegations contained significantly more rape stereotypes than true allegations. Across all conditions there was an inversion between inclusion of offender violence and victim blaming. However the true condition also differed from the false conditions in that as offender violence increased concepts implicitly excusing the offender on the basis of their sex drive decreased. Indeed it was apparent through the content analysis that true allegers spontaneously generated the offender's motivation as power seeking rather than achieving sexual gratification during highly violent episodes. Perhaps counter-intuitively in both categories of false account denial or minimisation of the rape did not co-occur with victim blaming.

Assessment of how attitudes towards rape stereotypes may influence their inclusion in a false statement revealed that a high belief in rape stereotypes correlated only with 
more violent accounts of rape and not any other specific rape stereotypes (as measured by IRMAS). This may support the argument that rape stereotypes describe the extreme end on a spectrum of offending because particularly violent attacks are over represented in the media.

That the generated and the withdrawn statements formed homogenous subsets in the Scheffe tests is suggestive that these statements may be drawn from the same population. This in turn may provide some support for the validity of using experimentally constructed false allegations in assessment of rape stereotypes and perhaps more widely in comparisons of true and false statements. However close matching for age was not possible in this study and this might be problematic as age of allegers was highlighted as an important variable for acceptance of rape stereotypes (Bryden \& Lengnick, 1997).

In terms of application, this study has identified some differences between true and false rape allegations but we would caution against these being used predictively on individual cases. The existence of rape stereotypes in an individual allegation are no evidence of its falsity. Indeed all the true statements contained some description of stereotypical concepts which were measured as rape stereotypes. At the general level it may be true that false allegations draw more on rape stereotypes which in turn draw on the more extreme accounts of real attacks, but this is no reason to argue that a particular account containing rape stereotypes is false. A more helpful conclusion to draw from this study may be explanatory rather than investigative; if true statements are less consistent with rape stereotypes than false allegations; and if rape stereotypes are held by investigators and jurors and judges; then one contributory explanation of 
low conviction rates in rape investigation might be that non-stereotypical, true accounts of rape are incredible. This area linking the amount of rape stereotype in false and specifically true rape witness statements requires substantial further research. 


\section{REFERENCES}

Allison, J.A. \& Wrightman, L.S. (1993). Rape: The misunderstood crime. London: Sage Publications.

Bryden, D.P. \& Lengnick, S. (1997) Rape in the criminal justice system. Journal of Criminal Law and Criminology, 87, 1197-1288.

Burt, M.R. (1980). Cultural myths and supports for rape. Journal of Personality and Social Psychology, 38, 217-230.

Burgess, A. \& Hazelwood, R. (2001) False Allegations In R.R. Hazelwood and A.W. Burgess (Eds.). Practical aspects of rape investigation (pp. 177-195) CRC Press: Boca Raton.

Cahill, A.J. (2000). Foucault, rape and the construction of the feminine body. Hypatia, 15, 43-64.

George, W.H. \& Martinez, L.J. (2002) Victim blaming in rape: Effects of victim and perpetrator race, type or rap and participant racism. Psychology or Women Quarterl,. 26, 110-119.

Home Office (2006) Home Office Consent Campaign Retrieved 17 August 2006 from http://www.homeoffice.gov.uk/documents/consent-campaign/ 
Johnson, M.K., Foley, M.A., Suengas, A.G., \& Raye, C.L. (1988). Phenomenal characteristics of memories for perceived and imagined autobiographical events. Journal of Experimental Psychology: General, 117, 371-376

Kahn, A.S. \& Mathie, V.A. (2000). Understanding the unacknowledged rape victim. In C.B. Travis and J.W. Write (Eds). Sexuality, society and feminism (pp. 377403) Washington DC: American Psychological Association.

Kelly, L., Lovett, J. \& Regan, L. (2005). A gap or a chasm? Attrition in reported rape cases. Home Office Research Study 293.

Kershner, R. (1996) Adolescent attitudes about rape. Adolescence, 31, 29-34.

Lonsway, K.A. \& Fitzgerald, L.F. (1994). Rape myths. Psychology of Women Quarterly, 18, 133-165.

Morton, T. \& Duck, J. (2003). Responding to risk information in the media: The role of attitudes towards the media and direct experience. Australian Journal of Psychology, 55, 54-59.

Ofshe, R. \& Walters, E. (1998). Making monsters. Society, 35, 2, 364-377.

PACE guidelines (2006) www.police.homeoffice.gov.uk/news-and-publications/ publication/operational-policing/PACECodeCH

Payne, D.L. Lonsway, K.A. \& Fitzgerald, L.F. (1999). Rape myth acceptance: Exploration of its structure and its measurement using the Illinois Rape Myth Acceptance Scale. Journal of Research in Personality, 33, 27-68. 
Peterson, Z.D. \& Muehlenhard, C.L. (2004). Was it rape? The function of women's rape myth acceptance and definitions of sex in labelling their own experiences, Sex Roles, 51, 129-144.

Rainbow, L. (1996). False rape allegations: First steps in a multidimensional approach to the detection of deception in rape statements. Unpublished Thesis. University of Liverpool, Liverpool.

Rassin, E.G.C. , Sleen, J. van der (2005). Characterics of true versus false allegations of sexuel offences. Psychological Reports, 97, 589-598.

Ryan, K.M. (1988). Rape and seduction scripts. Psychology of Women Quarterly, 12, 2, 237-247.

Stellar, M. and Kohnken, G. (1989). Criteria-based statement analysis. Credibility assessment of children's testimonies in sexual abuse cases. In D. Raskin (Ed.), Psychological techniques in law enforcement (pp. 217-245). New York: Springer-Verlag.

Vrij, A. (2000). Detecting lies and deceit. Chichester, UK: John Wiley.

Vrij, A. (2005). Criteria-Based Content Analysis: A qualitative review of the first 37 studies. Psychology, Public Policy, and Law, 11, 3-41.

Walker, A., Kershaw, C. \& Nicholas, S. (2006). Crime in England and Wales 2005/2006. UK: Home Office 
Woodhams, J., \& Grant, T. D. (2004). Statements of truth and deception: Using rapists' language to contrast maintained-as-true and withdrawn-as false rape allegations: Serious Crime Analysis Section - National Crime and Operations Faculty.

Woodhams, J., \& Grant, T. D. (2006). Developing a categorisation system for rapists' speech. Psychology, Crime, \& Law, 12(3), 245-260. 
Table 1. Descriptive statistics

\section{Statements}

Maintained Withdrawn Generated

\begin{tabular}{|c|c|c|c|c|}
\hline \multirow[t]{13}{*}{ Content codes } & & M (SD) & M (SD) & M (SD) \\
\hline & SA - She asked for it & $26.6(18.5)$ & $38.5(26.3)$ & $38.7(21.9)$ \\
\hline & NR - It wasn't really rape & $17.1(17.0)$ & $7.3(10.5)$ & $12.5(14.8)$ \\
\hline & MT - He didn't mean to & $12(14.0)$ & $12(15.0)$ & $12.1(9.8)$ \\
\hline & DE - Rape is a deviant & $5.9(6.5)$ & $15.0(23.4)$ & $8.76(12.4)$ \\
\hline & event & & & \\
\hline & RV - Rapists are violent & $38.4(26.6)$ & $28.2(24.0)$ & $27.6(17.5)$ \\
\hline & RSP - total percentage of & $22.0(8.35)$ & $47.2(14.66)$ & $47.0(11.4)$ \\
\hline & statement that conformed & & & \\
\hline & to rape stereotypes & & & \\
\hline & IRMAS Total & na & na & $31.2(7.3)$ \\
\hline & Total number of concepts & & & \\
\hline & present in allegation & $41.0(20.5)$ & $17.5(15.2)$ & $57.53(36.6)$ \\
\hline
\end{tabular}


Figure 1. Box plot of RSP for each condition

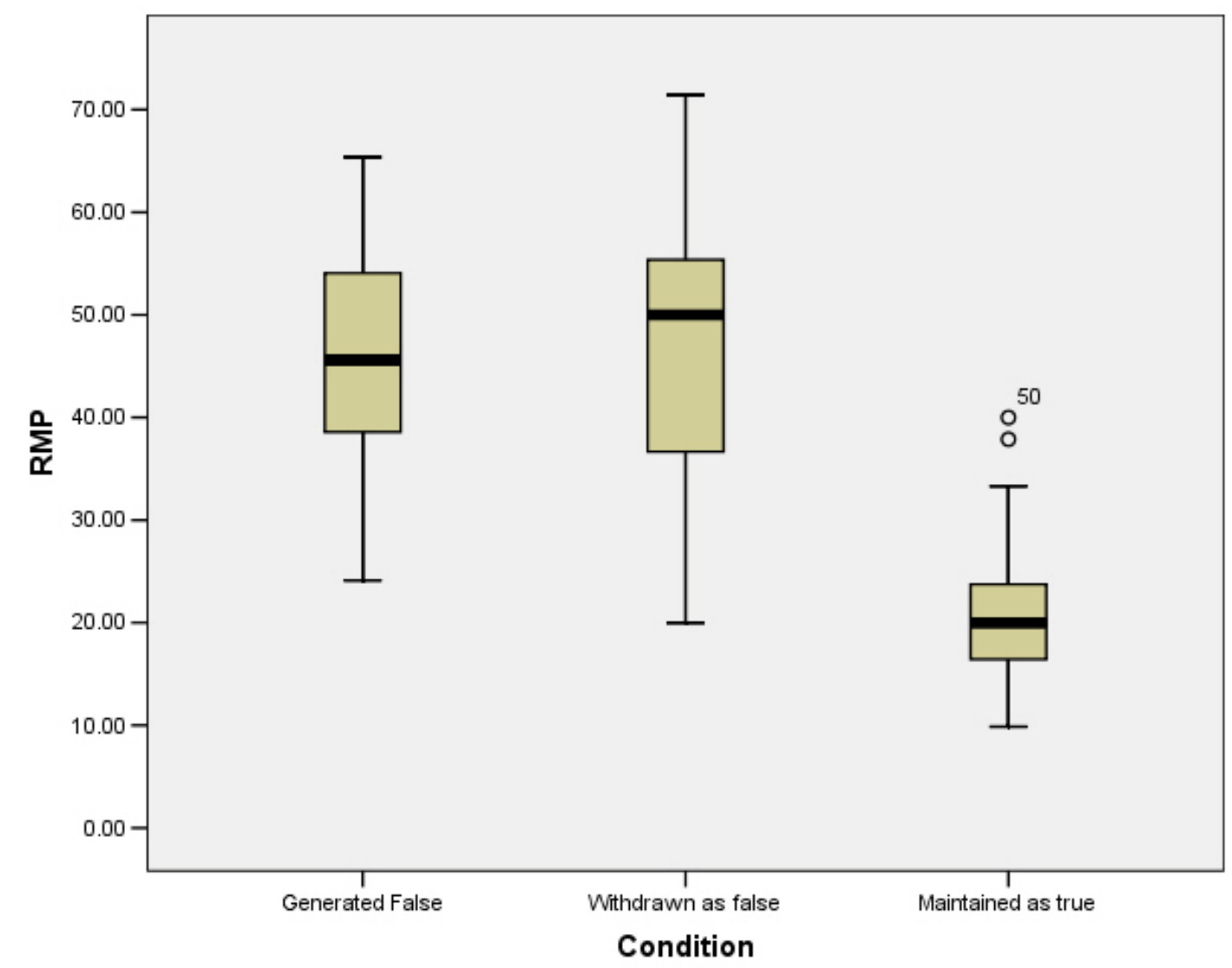




\section{Appendix 1}

Subcategories of the Illinois Rae Myth Acceptance Scale

She asked for it

It wasn't really rape

He didn't mean it

She wanted it

She lied

Rape is a trivial event

Rape is a deviant event

Filler item (not scored) 